\title{
Stage IV Fallopian Tube Cancer AJCC v6 and $v 7$
}

National Cancer Institute

\section{Source}

National Cancer Institute. Stage IV Fallopian Tube Cancer A/CC v6 and v7. NCI Thesaurus. Code C8963.

Stage IV includes: (Any T, Any N, M1). M1: Distant metastasis (excludes metastasis within the peritoneal cavity). (AJCC 6th and 7th eds.) 